lever press, the clear liquid which is expressed being added to that which has been clarified. It is now placed in boilers and heated up to about $60^{\circ} \mathrm{C}$., after which it is kept in the store vats, carefully sealed up.

The residue left in the press is subjected to a process of distillation in a current of steam, by which a spirit containing about 42 per cent. of alcohol is obtained.

The saké in the store vats contains about 15 per cent. of alcohol, and this fact shows that the fermentation is different to that effected by the Mucor racemosus, as described by Fitz. In his experiments he found that the presence of $4 \frac{1}{2}$ to $5 \frac{1}{2}$ per cent. of alcohol killed the ferment, whilst in the process above described, we find the ferment acting in such a way as to produce 15 per cent. There is, however, nothing improbable in the supposition that different species may possess different degrees of sensitiveness to alcohol, and that the species used here may be less easily affected than the one employed by Fitz.

There are, however, many points about the process which are obscure, and about which I cannot say anything at present, but further experiment will, it is hoped, throw light upon the obscurity now enreloping the subject. The above account has been given in the hope that it may prove of some interest to those engaged in the study of fermentation, and that it may lead to a more extended examination of the action of various species of fungus upon amylaceous substances.

University of Tokio, Japan

R. W. AtKINSON

\section{THE ORIGIN AND DISTRIBUTION OF} ORGANIC COLOUR

COLOUR, throughout the realms of organic nature, is a factor hitherto held to be the most capricious in its distribution and the least amenable to any finite law. So uncertain and variable indeed are its manifestations that its claims for the purposes even of specific diagnosis have long since been ignored by the comparative anatomist. Nevertheless, when examined more attentively, an amount of evidence may be adduced sufficient to warrant further inquiry as to whether there is not existent beneath the superficial stratum of apparent disorder, a harmonious under-current indicative of a derivation in the abstract from one of nature's simplest physical laws, namely, that of polarisation.

Directing brief attention first to the subject of colour as distributed among the animal world, it will at once be recognised that, with few exceptions, it is only amongst the classes lower in the scale than the mammalia that this element either attains or retains its full exuberance. Even within such limits it will be further found that the beautiful and recently-discovered law of natural selection, for the purposes of concealment or protection, has in many instances so influenced and subordinated all pre-existing characters as to have entirely masked or eliminated them. The lepidopterous order of the class Insecta most prominently illustrates this latter case ; the brilliant and varied hues of many members of this tribe being, as has been ably demonstrated, more especially by Mr. Alfred R. 'Nallace, in accord either with the flowers they most frequent, the objects upon or adjacent to which they rest in repose, or, still more remarkably, mimetically identical with those of other perfectly distinct species which owe their immunity from the attacks of birds to their peculiar acrid flavour.

The types among which have been first observed those peculiar colour-characteristics now to be submitted, are more particularly associated with aquatic life, and from these latter it has been found possible to extend and institute comparisons amongst almost every terrestrial group. Reference is here made to the dominance among the animal types in question of those so-called "complementary colours" familiar to all acquainted with the working of the polariscope. Of these colours in ques. tion, the combinations red and green, and blue and yellow are the most important, and it is surprising to find how frequently these reproduce themselves in nature.

Enumerating on this occasion merely a few instances, reference may be first made to those forms in which blue with its complementary hue, yellow, are found associated. Blue, as a rule, enters but to a comparatively trifling extent into the coloration of our indigenous fish fauna, but a remarkable and very gorgeous exception is afforded by the male of the Cuckoo Wrass (Labrus mixtus), which in its adult condition is resplendent with equally-distributed tints of the purest azure and most brilliant orange. These same complementary hues of blue and yellow obtain again in the male of another British fish, known as the Gemmeous Dragonet (Callionymus lyra). A conspicuous exotic example of the same colour-combination is presented by the Tesselated Parrot Fish of Ceylon (Scarus harice), characterised by its groundwork of azure blue decorated with an hexagonal network of golden yellow. Among the invertebrate division of the animal kingdom, the class of the Crustacea affords several interesting instances of a similar combination. Two of these belonging to the Decapodous order, Galathea strigosa and Scyllarus arctus, are of considerable size, having the deep orange hue of the general surface of their carapace variegated with bands and markings of brilliant blue. The Common Lobster (Homarus vulgaris), again, often "sports" into a bright blue variety, variously spotted and mottled with yellow. The legs of the Common Prawn (Pandalus annulicornis) are also most usually decorated with alternating rings of blue and orange. The marine copepods, more especially those of tropical seas, abound with instances of the association of these same two complementary hues. The class of the Mollusca is one among which blue as a pure colour but very rarely presents itself. There are, however, two Nudibranchs (Goniodoris colestis, Desh., and G. elegans, Cantraine) conspicuous for their ground colour of azure, accompanied in each instance by spots or lines of yellow. The lastnamed and finer of these two species, attaining a length of $2 \frac{1}{2}$ inches, and usually classed as a Mediterranean type, was collected by the writer on the rocky shore of the Cies Islands, Vigo Bay, in association with the dredging expedition of Mr. Marshall Hall's yacht Norna, during the spring of the year 1871 .

Pursuing the investigation among terrestrial types, the bird tribe-although it is necessary here to cite almost entirely tropical forms-produces abundant instances of the association of the same blue and yellow tints. The large Blue and Yellow Macaw (Ara ararauna) of South America forms a most conspicuous illustration, and the same two complementary hues will be found coupled together among innumerable other representatives of the parrot tribe, and likewise among the toucans. The most exquisitely beautiful blue bird yet known to science, the Azure Careba (Careba cyanea), is not altogether deficient of the complementary tint of yellow, several feathers of this colour appearing in the wings. One of the Cassowaries (Casuarius kaupi, Sclater), as figured in the Zoological Society's Proceedings for the year 1872 , is represented as having the skin of the upper and front portion of the throat coloured azureblue, while immediately behind and adjacent to this succeeds a patch of bright yellow. A still later and highly characteristic example is likewise afforded by the newly named Euphonia insignis of Messrs. Sclater and Salvin, figured at Pl. lii. Fig. I of the third part of the same Procecdings for this current year. Although our indigenous avifauna produces very few species in which the colour blue occupies a prominent position, the little Blue Tomtit (Parus cartulezs) is an exception which at the same 
time altogether conforms to that law of polarity here brought forward. Thus while the feathers on the head and back of this familiar species are of a bright cerulean. blue, those of the breast and under-surface are mostly yellow. Higher than the birds it seems useless to seek for the association of the two complementary tints under notice, though singularly enough one of these, the blue, turns up where it might be least anticipated, namely, amongst certain of the baboons, or Simiadæ, whose cheeks and re. markable posterior callosities are not unfrequently coloured bright cobalt. So late as the commencement of historic times our noble ancestors are reported to have supplied what nature had denied them in this department by the adorning of their persons with the juice of woad.

Turning now to the second complementary combination, that of red and green, it will be found to be far more extensively distributed even than that just discussed, birds, reptiles, fishes, and almost every class of the invertebrate kingdom supplying an important quota in which these colours are placed in juxtaposition. From among the first-named, the parrot tribe, woodpeckers, certain pigeons (Ptilonopus), trogans, and humming-birds, furnish abundant examples. Among lizards may be mentioned the Indian genus Calotes; while the ballan and corkwing wrasses, the Connemara sucker, and even the common stickleback in its breeding-dress, illustrate $f$ imiliar examples of our indigenous species of fish in which green and red constitute the two dominant hues. To this last-named list of fishes might be added innumerable exotic types. With the crustacean class green and red appears to be a scarce combination, but one marine Isopod (Spheroma), remarkable for the variation in colour of different individuals, supply an exceptional illustration, I having by me alive at the presert moment two examples, one of which is pale green, and the other scarlet. A spider, with whose technical name I am not familiar, but which often occurs on laurel bushes, has its body apple-green, supplemented with a bright red spot in the posterior region. Aphides, whose bodies are usually green, have frequently associated with the same scarlet or crimson eyes, and the same two colours will be found to be the prevalent tints of the larva of many lepidopterous insects. Green and red ascidians, worms, and zoophytes might likewise be enumerated, and the same combination is further traceable down to the Protozoa, and within the precincts of that debatable ground from whence both plants and animals take common origin.

Here, indeed, the subject assumes its most interesting and important phase, it being evidently at this initial point that the key and origin of the whole attendant phenomena are to be sought. Among a number of these humble unicellular organisms, including apparently as undoubted animals the Euglenæ or Astasiæ, and as true plants the Thecomonads and Volvocinæ, it will be found that the brilliant green hue of the general cell-substance is supplemented at one point by a brilliant scarlet speck, with which, in the case of animal organisms, the properties of a visual organ have been frequently associated. Though this interpretation does not meet with general support, it is remarkable how persistent is the presence of scarlet eyes among the more minute representatives of several invertebrate classes, including Insecta, Crustacea (some of these monocular), Annelids, and even Echinoderms, as typified by the starfish tribe. Advancing further on the vegetable side, the complementary colours of red and green, as first foreshadowed in unicellular Phy tozoa, become still more conspicuously associated. Altogether apart from the floral elements the colour red constantly accompanies the more general green cellular structure of the stems, petioles, and leaf venation of ordinary plants. One remarkable Mexican species, indeed, Pointsettia pulcherrima, affords an instance in which the whole foliage forming a rosette at the terminal portion of the plant is the most brilliant scarlet, while that of the lower part is simply green. Calladizms, Begonias, and many other types might be quoted, in which the same two colours are equally blended in the leaves. Among the flowerless cryptogams, again, the group of the Bryacex, or moss tribe, yields further analogous and corroborative data. The peculiar fimbriated structure or peristome, which upon the dehiscence of the operculum guards the aperture of the spore capsules in this group, being in the majority of instances bright scarlet or crimson. The brilliant floral elements of the phanerogamic class are not so easily subordinated to that law of polarity, which appears to have left its impress on the simpler vegetative parts. Cross-fertilisation and numerous other external conditions and surroundings 'have no doubt exercised their influence in this case to an extent parallel to, though not identical with, what obtains among the Lepidopterous group of the animal series. Even here, however, it is a matter of question whether red is not the colour most extensively distributed. Certain forest trees, for example, such as the larch, poplar, and hazel (female flower), form interesting exceptions among a group more usually altogether wanting in brilliant floral decoration, and in all of which instances red is the characteristic hue of the flowers they bear.

How, or in what manner, the varied colours of nature were first called into existence is a problem that yet remains to be solved. Without presuming to put forward or propose any arbitrary interpretation of this primeval derivation, the following data may be tentatively submitted. 'The initial term of the series, as represented amongst the lowest animals and lowest plants, and in the latter instance continued throughout the higher forms, is evidently the colour green. Associated with vegetable life it takes the form of chlorophyll, and as such is altogether dependent for its origin and existence upon the influence of solar light. Shut off from such influence, this element fails to produce itself, and vegetable tissues remain white, as instanced in the artificial cultivation of seakale and other culinary herbs. Prolonged isolation from such light, however, results in the arrest of the vital functions, and this circumstance fully explains the absence of chlorophyll producing vegetation below that depth in the ocean to which solar rays have access. ${ }^{1}$ Green again, is not a simple colour, but a combination of two othersblue and yellow. May not therefore its origin be remotely related to the effect of the solar rays, technically white and colourless, but yellow to the external senses as represented by ordinary sunshine and upon the artist's canvas, acting in concert with the blue ether of which our outer atmosphere is composed?

Given this initial colour green, the three primary hues of nature follow as a necessary consequence :-Blue and yellow by the resolution of the initial factor into its constituent parts, and red as its direct or reflex product in abeyance to the law of polarity. That this latter law exerts a considerable influence in the origin and distribution of those glorious tints of nature which may be said to constitute its most potent charm, will scarcely fail to recommend itself to the attention of those specially conversant with the physics of colour, and in whose hands this subject may prove susceptible of important development.

\section{W. SAVILLE KENT}

I Reference may be appropriately made here to the predominant colour or fixed deep-sea organisms, such as sponges and corals. In the hexactinellid sponge-form Phoronema (Holtenia) characteristic of abyssal depths, the colour, as observed by the writer in association with examples procured from colour, as observed by the writer in association with examples procured from
a depth of from five to six hundred fathoms off the coast of Portugal, and in a depth of from five to six hundred fathoms off the coast of Portugal, and in Norna recently referred to, was the most brilliant orange. This hue was likewise observed to be characteristic of the soft parts of the large deepwater branching coral Dendrophylliz ramea obtained in the same expedition. It will at once occur that this colour, orange, is directly complementary or porlyin that of the superincumbent mass of water, alway 